\title{
A model for calculating the mechanical demands of overground running
}

Authors: Adrian Gray ${ }^{1 *}$, Mark Andrews ${ }^{2}$, Mark Waldron ${ }^{1,3}$, David Jenkins ${ }^{4}$

${ }^{1}$ School of Science and Technology, University of New England, Armidale, NSW, Australia ${ }^{2}$ Queensland Academy of Sport, Nathan, QLD, Australia

${ }^{3}$ College of Engineering, Swansea University, Swansea, UK

${ }^{4}$ School of Human Movement and Nutrition Sciences, University of Queensland, St Lucia, QLD, Australia

*Dr Adrian Gray

Tel: +610267734511

Email: agray28@une.edu.au or ajgray.research@gmail.com

Orcid ID: 0000-0002-9302-9632

Word Count: 6066 words 


\section{Abstract}

2 An energy-based approach to quantifying the mechanical demands of overground, constant

3 velocity and/or intermittent running patterns is presented. Total mechanical work done ( $\left.W_{\text {total }}\right)$ is

4 determined from the sum of the four sub components: work done to accelerate the centre of mass

5 horizontally $\left(W_{h o r}\right)$, vertically $\left(W_{\text {vert }}\right)$, to overcome air resistance $\left(W_{\text {air }}\right)$ and to swing the limbs

$6\left(W_{\text {limbs }}\right)$. These components are determined from established relationships between running

7 velocity and running kinematics; and the application of work-energy theorem. The model was

8 applied to constant velocity running $\left(2-9 \mathrm{~m} \cdot \mathrm{s}^{-1}\right)$, a hard acceleration event and a hard deceleration

9 event. The estimated $W_{\text {total }}$ and each sub component were presented as mechanical demand (work

10 per unit distance) and power (work per unit time), for each running pattern. The analyses

11 demonstrate the model is able to produce estimates that: 1) are principally determined by the

12 absolute running velocity and/or acceleration; and 2) can be attributed to different mechanical

13 demands given the nature of the running bout. Notably, the proposed model is responsive to varied

14 running patterns, producing data that are consistent with established human locomotion theory;

15 demonstrating sound construct validity. Notwithstanding several assumptions, the model may be

16 applied to quantify overground running demands on flat surfaces. 


\section{Introduction}

23 Quantifying the loads athletes experience during training, competition and/or in research settings

24 is routine practice, with several methods employed across settings (Lambert \& Borresen, 2010).

25 The value, utility, practicality, limitations and future directions of load quantification methods

26 have been topics of discussion for several years (Aughey, 2011; Bourdon et al., 2017; Cummins,

27 Orr, O’Connor \& West, 2013; Gray, Shorter, Cummins, Murphy \& Waldron, 2018; Lambert \&

28 Borresen, 2010). Where training theory is considered a simple 'dose-response' relationship, there

29 is consensus that the exercise 'dose' experienced during training or competition can be described

30 in two ways; through objective measures of the work performed by the athlete (external load) or

31 as the relative biological (both physiological and psychological) stressors imposed on the athlete

32 (internal load) (Bourdon et al., 2017). The 'response' may be described by changes in performance

33 and/or adaptation, which notably, can be positive (e.g. performance increase, favourable

34 physiological adaptation, readiness to train) or negative (e.g. symptoms of fatigue, overuse injury,

35 reduced performance). Consistent with this understanding, several studies have implicated training

36 load as having influence over performance outcomes (Jobson, Passfield, Atkinson, Barton \& Scarf,

37 2009; Taha \& Thomas, 2003), athlete wellbeing (Lathlean, Gastin, Newstead \& Finch, 2019),

38 fatigue/readiness to perform (Halson, 2014) and injury (Schwellnus et al., 2016; Soligard et al.,

39 2016). To gain such insights, simultaneous monitoring of both external and internal load is

40 recommended, as this permits the evaluation of psychophysiological stress relative to the work

41 done. Indeed, reduced homeostatic disturbance to a given absolute work rate is a hallmark response

42 to exercise training (Blomqvist \& Saltin, 1983; Holloszy \& Coyle, 1984). This speaks to the

43 importance of adopting valid and reliable load monitoring methods (Lambert \& Borresen, 2010). 
45 The introduction of micro-technology devices (small units co-housing a global positioning system

46 (GPS) receiver and various micro-electrical mechanical systems) designed for sporting

47 applications has attracted considerable interest and discussion on how such data can and should be

48 treated to understand performance, guide training design and inform player management decisions,

49 particularly in field based team sports (Aughey, 2011; Cummins et al., 2013), where traditional

50 load monitoring methods e.g. heart rate monitoring, are unsuitable given the intermittent nature of

51 these sports (Bangsbo, Mohr \& Krustrup, 2006). Notwithstanding the limitations of micro-

52 technology devices (Malone, Lovell, Varley \& Coutts, 2017), it would seem they continue to be

53 used across many team sports as they readily provide kinematic summaries (time, distance,

54 velocity, acceleration) of the gross locomotor patterns during field-based training and competition.

55 Despite some microtechnology derived metrics demonstrating relationships with measures of

56 acute internal load (Impellizzeri, Rampinini, Coutts, Sassi \& Marcora, 2004) and/or readiness to

57 perform (Young, Hepner \& Robbins, 2012), the literature highlights several shortcomings and

58 opportunities to improve common techniques (Bourdon et al., 2017; Furlan, Osgnach, Andrews \&

59 Gray, 2014; Gray et al., 2018). For example, Bourdon et al. (2017) identify that the manner in

60 which commercial systems determine and report sprint and/or acceleration efforts, is often at odds

61 with how a coaches view said efforts, leading to misinterpretation. Similarly, Gray et al. (2018)

62 describe how the use of speed/acceleration zones (i.e. sample by sample binning of data according

63 to speed or acceleration) fragment work bouts, rather than painting clear pictures of the work

64 performed. Based on these discussions, the future of external load monitoring in team sports

65 appears to destined for improved wearable sensors (with technological advancements) and

66 advanced modelling techniques applied to present meaningful summary data to coaches and

67 athletes (Bourdon et al., 2017). 
69 In cycling, ergometers and power meters provide measures of mechanical work (total external

70 load) and power-time curves that are readily analysed to describe the intensity and distribution of

71 work. Whilst these technologies do not capture internal power (Brooks, Andrews, Gray \&

72 Osborne, 2013), it is arguably the gold standard method of measuring external load for cycling

73 exercise. Intuitively, the work/power method summates rather than fragments data, and uses

74 dimensionally appropriate units (as opposed to arbitrary units) for external load quantification.

75 Measuring mechanical work and power during overground running is not nearly as simple, but is

76 possible. Valuable insights such as the costly nature (both mechanically and metabolically) of

77 accelerated and decelerated running (Osgnach, Poser, Bernardini, Rinaldo \& di Prampero, 2010;

78 Pavei et al., 2019; Zamparo et al., 2019) have resulted from energy-based analyses, as such,

79 pursuing a field-based method of quantifying external load in terms of work and power seems

80 advantageous from multiple perspectives. Gray et al. (2018) proposed that following sport-specific

81 temporal classification of data sets into discrete movement categories e.g. walking, running,

82 colliding, wrestling; a model specific to each movement category could be applied to provide a

83 work-energy based description of each bout. Subsequent summation of all occurrences would yield

84 the total 'load' of the bout.

86 The movement demands of field-based team sports are well documented (Bangsbo et al., 2006;

87 Duthie, Pyne \& Hooper, 2003; Gabbett, King \& Jenkins, 2008; Wisbey, Montgomery, Pyne \&

88 Rattray, 2010), with many match analysis studies identifying that a large proportion of play is

89 spent in low-intensity locomotor activities (walking and jogging or $<3.5 \mathrm{~m} \cdot \mathrm{s}^{-1}$ ) interspersed with

90 brief ( 3- $10 \mathrm{~s})$ repeated bouts of high-intensity locomotor efforts (high speed running, explosive 
91 acceleration/deceleration). Given that the forward running gait is the predominant 'purposeful

92 movement' in team sport match play (Bloomfield, Polman \& O'Donoghue, 2007), a work-energy

93 model for this specific movement category is likely to be an essential component of the external

94 load profile of most field sports. Based on the Konig Theorem, Gray et al. (2018) conceptualised

95 a model for the determination of mechanical work done during overground forward running. This

96 study aims to apply this model to GPS derived velocity-time data to describe the mechanical power

97 and mechanical demand during three conditions: 1) constant velocity running (simulated); 2) a

98 maximal acceleration (simulated $40 \mathrm{~m}$ sprint); and 3) an intense deceleration (during on field

99 training). This analysis serves to demonstrate how an energy-based approach can quantify the

100 external load during over ground running of varied nature. It is hypothesised that the model will

101 produce estimates of mechanical power for continuous and intermittent running bouts, that are 102 appropriate for load monitoring applications.

\section{Methods}

\section{Theory}

105 The total mechanical work ( $\left.W_{\text {total }}\right)$ done during running can be partitioned into external work $\left(W_{\text {ext }}\right)$ 106 and internal work ( $W_{\text {int }}$ ) (Pavei et al., 2019a; Saibene \& Minetti, 2003), where $W_{\text {ext }}$ is the work 107 done to accelerate the centre of mass (COM) with respect to the environment and $W_{\text {int }}$ is the work 108 associated with the acceleration of body segments with respect to the COM. Therefore, total 109 mechanical work is given by:

$$
W_{\text {total }}=W_{\text {int }}+W_{\text {ext }}
$$

111 Furthermore, work done can be defined as either positive or negative. Positive work $\left(W^{+}\right)$is done 112 when the kinetic $(K E)$ and/or potential energies $(P E)$ of a mass are increased. Conversely, negative 
113 work $\left(W^{-}\right)$is done when the kinetic $(K E)$ and/or potential energies $(P E)$ of a mass are decreased.

114 These principles underpin all subsequent discussion.

116 In overground running on a level surface the COM is accelerated in the horizontal and vertical 117 planes (Cavagna, Saibene \& Margaria, 1964). Additionally, even in the absence of wind, air poses 118 a resistive force to the motion of the COM (di Prampero, 1986). Therefore, $W_{\text {ext }}$ can be considered 119 a function of the work done on the COM in the horizontal plane $\left(W_{h o r}\right)$, vertical plane $\left(W_{\text {vert }}\right)$ and 120 to overcome air resistance $\left(W_{\text {air }}\right)$. Therefore, external work is given by:

$$
W_{\text {ext }}=W_{\text {hor }}+W_{\text {vert }}+W_{\text {air }}
$$

122 Internal work $\left(W_{i n t}\right)$ is typically determined from changes in segment energies derived from motion 123 analysis (Pavei et al., 2019; Zamparo et al., 2019). However, Minetti (1998) provides a model 124 equation to predict $W_{\text {int }}$ from velocity, stride frequency, duty factor (the percentage of the stride 125 cycle in which a single limb is in the support phase) and a constant reflecting the inertial properties 126 of the limbs. In the absence of uneven terrain, varying loads or changes in wind direction and 127 speed, body mechanics are tightly coupled with forward velocity in running (Gray, Price, \& 128 Jenkins, In Press; Lee \& Farley, 1998; Mann \& Hagy, 1980; Nilsson, Thorstensson \& Halbertsma, 129 1985; Saito, Kobayashi, Myashita \& Hoshikawa, 1974; Zatsiorsky, Werner \& Kaimin, 1994). As 130 such, stride frequency and duty factor are readily modelled from running velocity (Gray et al., In 131 Press), enabling the subsequent determination of $W_{i n t}$ (Minetti, 1998). As $W_{i n t}$ is primarily 132 determined by limb kinematics, $W_{\text {limbs }}$ is used in the present study to denote this partition. 
135 The velocity-time curve used in the modelling process is assumed to represent the horizontal 136 motion of the COM during forward, overground running on a hard (not able to be deformed), 137 horizontal surface orthogonal to the earth's gravitational field; the runner's sagittal plane (the plane 138 upon which the runner's limbs tend to have their greatest angular motion) assumes a fixed vertical 139 orientation i.e. perpendicular to the running surface.

141 The following sections describe a method of determining $W_{\text {total }}$ during an overground running bout, 142 from the velocity-time curve of a GPS receiver. Common to all systems will be a finite sampling 143 frequency, as such the velocity-time curve of any running bout to be analysed will include a finite 144 number of samples $(n)$, a fixed time interval $\left(t_{i}\right)$ between samples. The formulae presented herein 145 are written for the $j^{\text {th }}$ sample, over a period of n, GPS samples.

147 Determination of mechanical work and power from GPS velocity data according to the above 148 theoretical framework was completed in four steps:

149 1. Predicting COM and limb kinematics from GPS velocity

150 2. Determining external work from GPS Velocity

151 3. Determining internal work from GPS Velocity

152 4. Summation to determine total mechanical work and power

\section{1. Predicting COM \& Limb Kinematics from GPS Velocity}

155 The kinematics of the COM and the limbs are tightly coupled to running speed. The motion of the $156 \mathrm{COM}$ in running is likened to a bouncing ball, where it is lowest during mid support and highest 
157 in mid-flight (Farley \& Ferris, 1998). Therefore, with each step (half stride) there is a vertical

158 oscillation of the COM, the vertical displacement ( $\Delta h$, from lowest to highest point) of which, has

159 been shown to vary linearly with movement velocity $\left(\mathrm{r}^{2}=0.444, \mathrm{p}=0.034, \mathrm{n}=90\right)$ (Ito, Komi,

160 Sjodin, Bosco \& Karlsson, 1983; Lee \& Farley, 1998) according to:

$161 \quad h=-0.008+0.004 \cdot v$

162 where $\Delta h$ is in $\mathrm{m}$, and $v$ in $\mathrm{m} \cdot \mathrm{s}^{-1}$.

163

164 Similarly, temporal limb kinematics have been shown to vary with 'steady state' running velocity.

165 Support duration decreases whilst swing duration is maintained or only modestly decreased at high

166 speeds (Nilsson et al., 1985). The percentage of the stride cycle in which a single limb is in the

167 support phase is termed the duty factor. Consequently, with increasing 'steady state' running

168 velocity, stride frequency $(f)$ increases whilst duty factor $(d)$ decreases. Given $f$ and $d$ are notable

169 determinants of mechanical power in locomotion (Minetti, 1998; Nardello, Ardigo \& Minetti,

170 2011), Gray et al. (In Press) have previously established regression equations relating stride

171 frequency and duty factor to running velocity in a sample of male football (soccer) players. The

172 regression equations determined were:

$173 f=0.026 \aleph^{2}-0.111 \times v+1.398$

174

$$
d=0.004 \rtimes^{2}-0.061 \rtimes v+0.50
$$

175 where $f$ is in $\mathrm{Hz}, d$ is \% (in decimal form), and $v$ in $\mathrm{m} \cdot \mathrm{s}^{-1}$. The application of equations 3,4 and 5

176 will soon be explained.

\section{2. Determining External Work from GPS Velocity}


179 External work done can be determined from changes in the kinetic $(K E)$ and potential energy $(P E)$

180 of the COM (Cavagna et al., 1964). The $K E$ of the COM is the vectorial sum of its horizontal

$181\left(K E_{h o r}\right)$ and vertical $\left(K E_{\text {vert }}\right)$ components, thus $W_{\text {hor }}$ is given by the change in $K E_{\text {hor }}$. The horizontal

182 velocity of the COM may be approximated by velocity-time data from a micro-technology device.

183 The resolution and sampling frequency of this technology is unlikely to detect within stride

184 fluctuations in COM motion, therefore this data can only be assumed to represent the gross forward

185 velocity, which is important nonetheless. On this basis, $W_{\text {hor }}$ can be expressed as:

186

$$
W_{h o r}^{j}={ }_{j=1}^{n} 0.5\left(\begin{array}{ll}
v_{j+1}^{2} & v_{j 1}^{2}
\end{array}\right)
$$

187 Importantly, where $v_{j+1}>v_{j-1}$ (as for acceleration), positive horizontal work $\left(W_{h o r}{ }^{+}\right)$is done by the

188 body. Where $v_{j+1}<v_{j-1}$ (as for deceleration), negative horizontal work $\left(W_{h o r}{ }^{-}\right)$is done by the body.

189 Furthermore, when determining work done from changes in KE, mass is a scaling factor and has 190 therefore been excluded such that units are $\mathrm{J} \cdot \mathrm{kg}^{-1}$.

192 With each step taken, the COM rises and falls by a height, $\Delta h$ (Lee \& Farley, 1998). The vertical 193 oscillation of the COM suggests the $K E_{\text {vert }}$ and $P E$ of the COM are in continual flux. Additionally, 194 the first law of thermodynamics implies $\triangle P E=\triangle K E_{v e r t}$, therefore either may be used to 195 approximate $W_{\text {vert }}$. In this approach, $\triangle P E$ will be used given $\Delta h$ can be predicted from velocity 196 using equation 3. $\triangle P E$ of the $\mathrm{COM}$ from its lowest to highest position and vice versa, equate to 197 the positive vertical work $\left(W_{\text {vert }}{ }^{+}\right)$and negative vertical work $\left(W_{\text {vert }}{ }^{-}\right)$done by the body, 198 respectively. Assuming, the COM rises and falls the same height in a step, it holds that $\left|W_{\text {vert }}{ }^{+}\right|$ $199=\left|W_{\text {vert }}\right|$. Thus, either can be expressed as:

200

$$
\left|W_{\text {vert }}^{j}\right|=\left|W_{\text {vert }}^{j}\right|=\sum_{j=1}^{n}\left(2 \cdot g \cdot h_{j} \cdot f_{j}\right)
$$


$201 \quad$ where $\Delta h_{\mathrm{j}}$ and $f_{\mathrm{j}}$ are predicted from $v_{\mathrm{j}}$ using equations 3 and 4 , respectively. Similar to equation 6 , 202 when determining work done from changes in PE, mass is a scaling factor and has again been 203 excluded such that units are $\mathrm{J} \cdot \mathrm{kg}^{-1}$.

204

205 Air resistance $\left(F_{\text {air }}\right)$ is an external force applied by the volume of air that meets and passes around 206 the surface of a body. It can be mathematically expressed as a function of ambient air density $(\rho)$, 207 projected frontal surface area $\left(A_{p}\right)$, the square of the relative air speed $(S)$ and a drag coefficient $208\left(C_{d}\right)$ according to:

209

$$
F_{\text {air }}=0.5 \times \times A \times S^{2} \times C_{d}
$$

210 Air density varies with $T$ and $B P$, therefore with knowledge of these values, ambient air density $211(\rho)$ can be estimated according to:

212

$$
=\frac{273 \times{ }_{0} \times B P}{760 \times T}
$$

213 with the unit $\mathrm{kg} \cdot \mathrm{m}^{-3}$, where $B P$ is in $\mathrm{mmHg}, T$ is in ${ }^{\circ} \mathrm{C}$ and $\rho_{o}=1.293 \mathrm{~kg} \cdot \mathrm{m}^{-3}$ (air density at sea 214 level and $273 \mathrm{~K})$.

215

216 Projected frontal surface area of a human running is $26 \%$ of total body surface area $(B S A)$ 217 (Davies, 1980; Pugh, 1971, 1976; Shanebrook \& Jaszczak, 1976), which can be determined using 218 established prediction equations (DuBois \& DuBois, 1916; Shuter \& Aslani, 2000). Applying a 219 BSA prediction equation (Shuter \& Aslani, 2000), $A_{p}$ can be determined according to:

220

$$
A=0.26\left(94.9 \times h t^{0.655} \times M^{0.441}\right)
$$

221 with the unit $\mathrm{m}^{2}$, where $h t=$ standing height in $\mathrm{m}$ and $M=$ body mass in $\mathrm{kg}$. 
223 Using varied methodological approaches, the $C_{d}$ for humans running ranges from 0.7 to 1.1

224 (Davies, 1980; Pugh, 1971; Shanebrook \& Jaszczak, 1976; Walpert \& Kyle, 1989). In the present

225 model, $C_{d}=1$ will be adopted.

226

227 In calm air, the movement velocity $(v)$ of a runner determines the relative air speed, thus $v=S($ di

228 Prampero, 1986). Under these conditions, the mechanical work done to overcome air resistance

$229\left(W_{\text {air }}\right)$ is proportional to the cube of the runners forward velocity i.e. $v^{3}$ and can be expressed as:

230

231

$$
W_{\text {air }}^{j}=\sum_{j=1}^{n}\left(\frac{0.5 \cdot \cdot A \cdot v_{j}^{3} \cdot C_{d_{j}} \cdot t_{i}}{M}\right)
$$

232 with the unit $\mathrm{J} \cdot \mathrm{kg}^{-1}$, where $\rho, \mathrm{A}_{\rho}, v, C_{d}, t_{i}$ and $M$ are substituted as previously defined.

\section{3. Determining Internal Work from GPS Velocity}

235 Internal work primarily describes the work done to swing the limbs $\left(W_{\text {limbs }}\right)$ and is typically 236 determined from changes in segment energies derived from motion analysis. However, Minetti 237 (1998) provides a model equation to predict the mechanical work done to swing the limbs, per unit 238 distance travelled $\left(D_{\text {limbs }}\right)$, in walking and running from velocity, stride frequency and duty factor 239 as follows:

240

$$
D_{\text {limbs }}=q \cdot v^{2} \cdot f\left(1+\left(\frac{d}{1 d}\right)^{2}\right)
$$

241 where $q=0.1$, and is a constant reflecting the inertial properties of the limbs and the mass

242 partitioning between the limbs and the rest of the body (Minetti, 1998) (units are $\mathrm{J} \cdot \mathrm{kg}^{-1} \cdot \mathrm{m}^{-1}$ ). This

243 equation allows within and between segment energy transfer and takes the absolute sum of positive 
244 and negative work performed by the limbs (Minetti, 1998; Nardello et al., 2011). On this 245 understanding, $W_{\text {limbs }}$ can be expressed as:

$$
W_{\text {limbs }}^{j}=\sum_{j=1}^{n}\left(q \cdot v_{j}^{3} \cdot f_{j}\left(1+\left(\frac{d_{j}}{1 d_{j}}\right)^{2}\right) \cdot t_{i}\right)
$$

247 where $f_{j}$ and $d_{j}$ are predicted from $v_{j}$ using equations 4 and 5, respectively (units are $\mathrm{J} \cdot \mathrm{kg}^{-1}$ ).

\section{Summation to Determine Total Mechanical Work, Power and Demand}

250 Equations 6, 7, 11 and 13 define components $\left(W_{\text {hor }}^{+}, W_{\text {hor }}^{-}, W_{\text {vert }}{ }^{+}, W_{\text {vert }}, W_{\text {air }}\right.$ and $\left.W_{\text {limbs }}\right)$ of the 251 total mechanical work done $\left(W_{\text {total }}\right)$ for running at a given velocity. As such, $W_{\text {total }}$ can be expressed 252 as:

253

$$
W_{\text {total }}^{j}={ }_{j=1}^{n}\left(\left|W_{\text {vert }}^{j}\right|+\left|W_{\text {vert }}^{j}\right|+\left|W_{\text {horiz }}^{j}\right|+W_{\text {limbs }}^{j}+W_{\text {air }}^{j}\right)
$$

254 where $W_{\text {total }}$ is in $\mathrm{J} \cdot \mathrm{kg}^{-1}$.

255

256 The total mechanical power $\left(P_{\text {total }}\right)$ can be determined by dividing by the time interval according 257 to:

$258 \quad P_{\text {total }}^{j}=\frac{W_{\text {total }}^{j}}{t_{i}}$

259 units are $\mathrm{W} \cdot \mathrm{kg}^{-1}$. To determine the mechanical power of any sub component in the model e.g. $P_{\text {hor }}{ }^{+}$

260 from $W_{h o r}{ }^{+}$, the same approach can be applied.

262 The total mechanical demand $\left(D_{\text {total }}\right)$ can be determined by dividing mechanical power $\left(P_{\text {total }}\right)$ by 263 the running velocity according to: 


$$
D_{\text {total }}^{j}=\frac{P_{\text {total }}^{j}}{v^{j}}
$$

265 units are $\mathrm{J} \cdot \mathrm{kg}^{-1} \cdot \mathrm{m}^{-1}$, a customary unit for the mechanical and metabolic cost of locomotion 266 (Minetti, 1998). To determine the mechanical demand of any sub component in the model e.g. $267 D_{h o r}{ }^{+}$from $P_{h o r}{ }^{+}$, the same approach can be applied.

\section{Participants}

269 For condition 1), data that simulated constant velocity running were manually developed therefore 270 no participants were required. For conditions 2) and 3), ten elite Australian football players were 271 recruited from an Australian Football League (AFL) club to participate. The participants 272 represented a cross section of age, size, and running ability of elite Australian football players 273 (mean \pm SD age: $25.4 \pm 4.1$ years, body mass: $89.3 \pm 11.4 \mathrm{~kg}$, stature: $188.9 \pm 7.1 \mathrm{~cm}$ ). Informed 274 consent was gained prior to participation and the study was approved by an ethics committee of 275 The University of Queensland.

\section{$276 \quad$ Procedures}

277 Data sets simulating constant velocity running at $2,3,4,5,6,7,8,9$ and $10 \mathrm{~m} \cdot \mathrm{s}^{-1}$ were prepared 278 for analysis in R (R, Vienna, Austria), which determined mechanical work done based on the 279 model described above. Environmental conditions were standardised $\left(\mathrm{BP}=760 \mathrm{mmHg}, \mathrm{T}=23^{\circ} \mathrm{C}\right.$ 280 and no wind) and mean stature $(189 \mathrm{~cm})$ and body mass $(89.3 \mathrm{~kg})$ of the participants were used in 281 the calculations. The relationships between constant velocity running and mechanical power are 282 presented.

284 GPS data (SPIpro, GPSports, Canberra, Australia) collected at $5 \mathrm{~Hz}$ during a pre-season sprint 285 testing session ( $3 \times 40 \mathrm{~m}$ sprints on an outdoor tartan athletics track) were downloaded (GPSports, 
286 Team AMS, Canberra, Australia) and reviewed to set parameters for an exponential function 287 (Chelly \& Denis, 2001; P. E. di Prampero et al., 2005) that represented the group's sprint 288 performance. This was: $\quad v_{t}=v_{\max } \rtimes\left(1-e^{-t}\right)$

289 where $v_{\mathrm{t}}$ is the modelled running velocity in $\mathrm{m} \cdot \mathrm{s}^{-1}, v_{\max }$ is the maximal velocity reached during the 290 sprint in $\mathrm{m} \cdot \mathrm{s}^{-1}$, and $\tau$ is the time constant in $\mathrm{s}$. The mean $\pm \mathrm{SD} v_{\max }$ of the participant group was $2919.16 \pm 0.42 \mathrm{~m} \cdot \mathrm{s}^{-1}$, which was substituted into equation 17 , along with $\tau=1.4$. The modelled 292 velocity-time curve (reproduced at $5 \mathrm{~Hz}$ ) was visually inspected and considered to adequately 293 represent the sprint performance of the participant group (Figure 1). This velocity-time data was 294 then imported for analysis in R, as described above. The modelled changes in mechanical work 295 and power over the duration of the simulated sprint are presented.

297 GPS data recorded during a regular season, field-based training session were downloaded and 298 reviewed to identify each participant's peak deceleration not attributed to a collision or fall. This 299 discrete deceleration event was exported to Microsoft Excel (Microsoft Corp., Redmond, USA) 300 where kinematic variables used to describe the nature of deceleration events were determined; 301 duration $(\mathrm{s})$, initial velocity $\left(\mathrm{m} \cdot \mathrm{s}^{-1}\right)$, final velocity $\left(\mathrm{m} \cdot \mathrm{s}^{-1}\right)$ and peak deceleration $\left(\mathrm{m} \cdot \mathrm{s}^{-2}\right)$. These 302 events were then opened for analysis in R. The application used the raw, exported $5 \mathrm{~Hz}$ velocity303 time curves to determine the mechanical work done based on the model described above. 304 Participant characteristics (stature, body mass and maximum running velocity) were individualised 305 in this deceleration analysis. The modelled changes in mechanical work and power during the 306 participant's decelerations are presented. The data of Participant 6 are presented graphically to 307 illustrate how the model operates. Participant 6 was selected on the basis of mass, stature and sprint 
308 ability, which are consistent with mean values for elite Australian football players (Buttifant, 1999;

309 Young et al., 2005).

310

311 Results

312 Consistent with the units defined in equations 14, 15 and 16, all presented estimates of

313 mechanical work, power and demand are expressed relative to body mass for comparative

314 purposes.

\section{Constant Velocity Running}

316 During simulated constant velocity running $W_{\text {hor }}{ }^{+}$and $W_{\text {hor }}$, are equal to zero. Figure 2 shows the 317 changes in $D_{\text {vert }}{ }^{+}, D_{\text {vert }}, D_{\text {air }}$ and $D_{\text {limbs }}$ (components of mechanical demand) for constant velocity 318 running from $2-10 \mathrm{~m} \cdot \mathrm{s}^{-1} . D_{\text {total }}$ was minimised at $\sim 4 \mathrm{~m} \cdot \mathrm{s}^{-1}$ before increasing curvilinearly with 319 running velocity (Figure 3). $P_{\text {total }}$ (total mechanical power) increased in an exponential manner 320 from $\sim 4.4 \mathrm{~W} \cdot \mathrm{kg}^{-1}$ at $2 \mathrm{~m} \cdot \mathrm{s}^{-1}$, up to $\sim 42 \mathrm{~W} \cdot \mathrm{kg}^{-1}$ at $10 \mathrm{~m} \cdot \mathrm{s}^{-1}$. At a low running speed of $3 \mathrm{~m} \cdot \mathrm{s}^{-1}$, the 321 mechanical work done to raise and lower the COM $\left(W_{\text {vert }}{ }^{+} \& W_{\text {vert }}{ }^{-}\right)$accounted for $\sim 68 \%$ of the 322 total mechanical work done, followed by $W_{\text {limbs }}$ and $W_{\text {air }}$, with $\sim 30 \%$ and $2 \%$ respectively. At 9 $323 \mathrm{~m} \cdot \mathrm{s}^{-1}, W_{\text {limbs }}$ was the primary contributor to mechanical demand $(\sim 77 \%)$, followed by $W_{\text {vert }}{ }^{+} \&$ $324 W_{\text {vert }}{ }^{-}(\sim 15 \%)$ and $W_{\text {air }}(\sim 8 \%)$. The relative contributions from each component in the model for 325 running velocities between 2 and $10 \mathrm{~m} \cdot \mathrm{s}^{-1}$ are shown in Figure 4.

$$
\text { **** Figure 2, } 3 \& 4 \text { near here*** }
$$

\section{Acceleration}

328 Mechanical demand reached a peak of $6.8 \mathrm{~J} \cdot \mathrm{kg}^{-1} \cdot \mathrm{m}^{-1}$ just $0.4 \mathrm{~s}$ into the maximal $40 \mathrm{~m}$ sprint $(\sim 6 \mathrm{~s}$ 329 in total), at a horizontal velocity of $2.3 \mathrm{~m} \cdot \mathrm{s}^{-1}$ and an acceleration of $9.87 \mathrm{~m} \cdot \mathrm{s}^{-2}$, before reducing to 
330 almost half of this value $\left(3.45 \mathrm{~J} \cdot \mathrm{kg}^{-1} \cdot \mathrm{m}^{-1}\right)$ as $v_{\max }$ was attained (Figure $5 \mathrm{~b}$ ). Mechanical power

331 increased rapidly over the first second, followed by a slow progression toward a peak value of $\sim 31$

$332 \mathrm{~W} \cdot \mathrm{kg}^{-1}$ at a horizontal velocity and acceleration of $\sim 9 \mathrm{~m} \cdot \mathrm{s}^{-1}$ and $0.24 \mathrm{~m} \cdot \mathrm{s}^{-2}$, respectively (Figure

$3335 \mathrm{c})$. The total work done over the whole sprint was estimated to be $160.6 \mathrm{~J} \cdot \mathrm{kg}^{-1}$. Of this, $54.2 \%$

334 was attributed to swinging the limbs back and forth $\left(W_{\text {limbs }}\right), 25.1 \%$ to accelerate the COM

335 horizontally $\left(W_{\text {hor }}{ }^{+}\right), 14.7 \%$ to accelerate and decelerate $\left(W_{\text {vert }}{ }^{+} \& W_{\text {vert }}{ }^{-}\right)$the COM vertically and

$3365.8 \%$ to overcome air resistance $\left(W_{\text {air }}\right)$. Figure 7 a shows the mechanical power curves for each

337 component of the model during the simulated sprint.

338

$* * * *$ Figure 5 near here $* * * *$

\section{Deceleration}

340 The mean \pm SD duration $(\mathrm{s})$, initial velocity $\left(\mathrm{m} \cdot \mathrm{s}^{-1}\right)$, final velocity $\left(\mathrm{m} \cdot \mathrm{s}^{-1}\right)$ and peak deceleration

$341\left(\mathrm{~m} \cdot \mathrm{s}^{-2}\right)$ of the deceleration curves collected from the team training session were $2.1 \pm 0.2 \mathrm{~s}, 6.4 \pm$

$342 \quad 1.1 \mathrm{~m} \cdot \mathrm{s}^{-1}, 1.2 \pm 0.8 \mathrm{~m} \cdot \mathrm{s}^{-1}$ and $-5.3 \pm-0.6 \mathrm{~m} \cdot \mathrm{s}^{-2}$, respectively. Figure 6 a shows the velocity-time

343 curve of Participant 6 during hard voluntary deceleration. All other participants had similar shaped

344 curves despite some variation in the initial and final velocities. The mechanical demand reached a

345 peak of $8.1 \mathrm{~J} \cdot \mathrm{kg}^{-1} \cdot \mathrm{m}^{-1}$ just $1.5 \mathrm{~s}$ into the $2.4 \mathrm{~s}$ deceleration event, at a horizontal velocity of 4.0

$346 \mathrm{~m} \cdot \mathrm{s}^{-1}$ (Figure $6 \mathrm{~b}$ ). This occurred at the same time as the peak deceleration $\left(-6.6 \mathrm{~m} \cdot \mathrm{s}^{-2}\right)$. Mechanical

347 power typically began relatively high (dependent on the initial velocity), increased to a peak under

348 intense deceleration and reduced to a minimum once velocity tended towards a constant, low value.

349 For Participant 6, mechanical power was initially high, but stable at $\sim 22 \mathrm{~W} \cdot \mathrm{kg}^{-1}$, before peaking

350 at $43.5 \mathrm{~W} \cdot \mathrm{kg}^{-1}$, then returning to zero (Figure $6 \mathrm{c}$ ). This peak occurred just prior to the peak

351 deceleration. Moreover, for Participant 6, the total work done over the whole 2.4 s deceleration

352 was estimated to be $58 \mathrm{~J} \cdot \mathrm{kg}^{-1}$. Of this, $\sim 52 \%$ was attributed to decelerating the COM horizontally 
$353\left(W_{\text {hor }}{ }^{-}\right), \sim 32 \%$ to swinging the limbs back and forth $\left(W_{\text {limbs }}\right), \sim 14 \%$ to accelerate and decelerate

$354\left(W_{\text {vert }}{ }^{+} \& W_{\text {vert }}{ }^{-}\right)$the COM vertically and $1 \%$ to overcome air resistance $\left(W_{\text {air }}\right)$. Figure $7 \mathrm{~b}$ shows the 355 mechanical power curves for each component of the model during Participant 6's deceleration 356 event.

\section{Discussion and Implications}

360 This study describes and applies a new energetic approach to model the demands of non-steady 361 state overground running from GPS data, that offers insights into the mechanical demands of 362 running. Application of the model to constant velocity, accelerated and decelerated running has 363 demonstrated the manner by which the model quantifies the mechanical demands of varied running 364 patterns. Specifically, the analysis highlights that the model is able to produce estimates of 365 mechanical demand that: 1) are principally determined by the absolute running velocity and/or 366 acceleration; and 2) can be attributed to different mechanical loads on the runner given the nature 367 of the running bout.

369 There is a tenfold variation $\left(1.81-18.3 \mathrm{~W} \cdot \mathrm{kg}^{-1}\right)$ in estimates of total mechanical power for running 370 at 3.6-3.9 $\mathrm{m} \cdot \mathrm{s}^{-1}$; largely attributable to whether within and between-segment energy transfer is 371 permitted in the model (Arampatzis, Knicker, Metzler \& Bruggemann, 2000). By allowing within 372 and between segment energy transfer when deriving $W_{\text {limbs }}$ and taking the absolute sum of positive 373 and negative work throughout, the present analysis yields a mechanical power of $\sim 6 \mathrm{~W} \cdot \mathrm{kg}^{-1}$ for 374 running at $3.75 \mathrm{~m} \cdot \mathrm{s}^{-1}$. This approach was adopted to permit derivation of metabolic power in future 375 analyses (Zatsiorsky, 1997). Despite the values in this analysis falling neatly within those reported 
376 in the literature, the general lack of consensus regarding methodological approach (Arampatzis et

377 al., 2000), makes it difficult to comment on the validity of the mechanical power estimates

378 produced. Nonetheless, applying the model to constant velocity running clearly showed that the

379 mechanical demands of running increased with velocity, independent of acceleration (Figure 3).

380 As $W_{\text {int }}$ is intuitively related to stride frequency, it is not surprising that $W_{\text {int }}$ tends to increase with

381 speed for both walking and running (Nardello et al., 2011). In contrast, $W_{e x t}$ tends to decrease with

382 constant velocity running (Cavagna \& Kaneko, 1977). The greater increases in $W_{i n t}$ compared to

$383 W_{\text {ext }}$ result in overall increases in $W_{\text {total }}$ with velocity. Figure 4 reflects these well-accepted concepts

384 in the human locomotion literature, with $P_{\text {total }}$ primarily attributed to $P_{\text {vert }}$ at low running velocities 385 and $P_{\text {limbs }}$ at high running velocities.

387 Collectively, the model suggests continual shifts in the primary mechanical demands of the energy 388 expended during intermittent running. The model describes accelerating the COM vertically as the 389 greatest mechanical demand during low velocity, low acceleration running efforts (Figure 4);

390 swinging the limbs as the greatest mechanical demand during high velocity, low acceleration 391 running efforts (Figure 7); and accelerating/decelerating the COM horizontally as the greatest 392 mechanical demand during low-moderate velocity, high acceleration/deceleration running efforts 393 (Figure 7). These general outcomes of the model are consistent with our understanding of human 394 locomotion (Cavagna \& Kaneko, 1977; Doke, Donelan \& Kuo, 2005; Farley \& Ferris, 1998) and 395 the findings of recent experimental work on the sprint acceleration (Pavei et al., 2019) and shuttle 396 running (Zamparo et al., 2019) mechanics/energetics. Indeed, a mechanical power analysis of 397 maximal $20 \mathrm{~m}$ sprints using a 35-camera motion capture system reports peak power values of $\sim 30$ $398 \mathrm{~W} \cdot \mathrm{kg}^{-1}$, with the forward (horizontal) acceleration of the COM, vertical acceleration of the COM 
and acceleration of the limbs relative to the COM, accounting for $50 \%, 9 \%$ and $41 \%$ of the total

400 power, respectively. To enable comparison, by removing the $W_{\text {air }}$ component from the present 401 model and applying it to the velocity-time curve produced by equation 17 over a 3-second period 402 (to simulate a $20 \mathrm{~m}$ sprint), $W_{h o r}, W_{\text {vert }}$ and $W_{\text {limbs }}$ were found to account for $49 \%, 16 \%$ and $35 \%$, 403 respectively. Thus, the present model provides field-based estimates of mechanical power 404 partitions in similar proportions to gold standard laboratory measurements. Similarly, the 405 acceleration/deceleration data presented are consistent with the findings of Zamparo et al. (2019); 406 which demonstrates athletic males produce greater mechanical power during maximal deceleration 407 than maximal acceleration.

409 It is now commonly accepted that acceleration and deceleration are energetically costly running 410 patterns (Polglaze \& Hoppe, 2019). The model estimates $D_{\text {total }}$ during constant velocity running at $4119 \mathrm{~m} \cdot \mathrm{s}^{-1}$ (approximate peak running velocity of elite field sport athletes) to be $3.3 \mathrm{~J} \cdot \mathrm{kg}^{-1} \cdot \mathrm{m}^{-1}$ (Figure 412 3). Notably, this falls short of the $D_{\text {total }}$ values observed during maximal accelerations $\left(6.8 \mathrm{~J} \cdot \mathrm{kg}^{-}\right.$ $\left.41{ }^{1} \cdot \mathrm{m}^{-1}\right)$ and decelerations $\left(8.1 \mathrm{~J} \cdot \mathrm{kg}^{-1} \cdot \mathrm{m}^{-1}\right)$. Moreover, Figures 5 and 6 clearly demonstrate the 414 mechanical demand reaches a peak when the rate of change in velocity is greatest. Figure 7 415 confirms it is indeed the $W_{h o r}{ }^{+}$and $W_{h o r}{ }^{-}$components of the model that are responsible for raising 416 the mechanical demand of such running events. These comparisons highlight the model readily 417 captures the 'costly' nature of acceleration and deceleration events. In contrast, the model suggests 418 that in calm conditions overcoming air resistance presents a very minor contribution to the overall 419 mechanical demand of running. Indeed, despite increasing with running velocity, at $10 \mathrm{~m} \cdot \mathrm{s}^{-1}, D_{\text {air }}$ 420 accounts for less than $10 \%$ of $D_{\text {total }}$ (Figure 4), which is also consistent with previous research (di 421 Prampero, 1986; Pugh, 1971; Ward Smith, 1984). 
423 The model proposed herein and its applications are based on the following assumptions:

424 1) The vertical displacement of the COM, stride frequency and duty factor are predicted from 425 forward velocity according to equations 3,4 and 5. Firstly, these relationships have been derived 426 from constant velocity overground running in sub-elite athletes (Gray, et al., In Press; Lee \& 427 Farley, 1998). Pavei et al. (2019) report stride frequency and duty factor during maximal $20 \mathrm{~m}$ 428 sprints in a laboratory setting, showing stride frequency is almost constant at $\sim 2 \mathrm{~Hz}$ throughout the 429 accelerated running bout; whilst duty factor quickly declined from $\sim 0.38$ to plateau at $\sim 0.2$ after $430 \sim 10 \mathrm{~m}$. Applying these values to the first 3 seconds of the $40 \mathrm{~m}$ sprint data in this study (to evaluate 431 the error introduced by applying constant speed kinematics to accelerated running) resulted in a 432 mean change in $P_{\text {total }}$ of $1.3 \%$, however this was the net effect of up to $\sim 8 \%$ underestimation in the 433 initial stages of the sprint and up to $\sim 10 \%$ overestimation in the latter stages. To the authors 434 knowledge, no data exists that allows for similar comparisons during deceleration and/or change 435 of direction, as such the magnitude of error introduced for these running patterns is unknown. 436 Secondly, effects of fatigue (Brueckner et al., 1991), size (Saibene \& Minetti, 2003), running 437 surface (Lejune, Willems \& Heglund, 1998), running ability (Paradisis et al., 2019) and other 438 contextual factors on these kinematic variables are not taken into consideration. With 439 improvements in wearable technology, direct measurement of these variables may replace these 440 prediction equations, however until such time, this serves as a first approximation.

442 2) Vertical work done by the COM is determined, on the understanding that the COM rises and 443 falls to the same height in a step. Studies suggest this is a simplification of the 'true' trajectory of 444 the COM during running (Cavagna, 2006; Ito et al., 1983; Lee \& Farley, 1998). Furthermore, the 
445 model assumes the runner's sagittal plane is always vertical, such that the oscillation of the COM

446 can be quantified by changes in PE. This assumption, does not consider the observation that

447 runner's lean (change the orientation of the sagittal plane) during 'bend running' and markedly

448 lower their COM during more abrupt changes of running direction. Movement in the coronal plane

449 is assumed to be negligible and given that GPS receivers have insufficient resolution to detect

450 within-stride fluctuations in forward velocity, the positive and negative work associated with the

451 propulsive and braking forces during stance are also negated. These assumptions appear to result

452 in overestimations, based on comparisons with recent experimental works (Pavei et al., 2019),

453 however it is not possible to quantify the magnitude of error this introduces based on current

454 literature.

455

456 3) Mechanical internal work was predicted using the prediction equation of Minetti (1998), which

457 is based on several assumptions itself, namely the four limbs are straight segments with constant 458 inertial properties at all running speeds. This is clearly a simplification of the 'true' limb structure 459 and human gait and it may have led to an overestimation of the mechanical demand of swinging 460 the limbs. The equation has proven a robust alternative to direct measurement during constant 461 speed (Nardello et al., 2011) and short sprint running (Pavei et al., 2019). However, during 462 accelerated running where limb configurations are changing on a step-by-step basis (Nagahara, 463 Matsubayashi, Matsuo \& Zushi, 2014; Pavei et al., 2019), the compound factor ' $q$ ' decays 464 exponentially from $\sim 0.22$ to reach an asymptote of $\sim 0.1$ (as in constant speed running). Where $q$ 465 is appropriately defined, it seems this prediction equation provides values within $1 \mathrm{~W} \cdot \mathrm{kg}^{-1}$ of gold 466 standard measures (Pavei et al., 2019), however more work is needed to describe how $q$ varies 
467 during deceleration and change of direction at varied intensities. Until these data are available it

468 seems reasonable to fix $q$ between 0.1 and 0.2 for intermittent running bouts.

470 4) The model is presently described to apply to an environmental state where there is strictly 'no

471 wind' (equation 11). As such the additional mechanical demand of overcoming a head-wind

472 (added resistive force) or reduced mechanical demand in the presence of a tail-wind is not 473 considered. Where wind direction and speed are able to be measured, equation 11 can be modified

474 to accommodate these effects. Using the participant characteristics in this analysis, a $5 \mathrm{~m} \cdot \mathrm{s}^{-1} \mathrm{head}$ 475 wind when running at $10 \mathrm{~m} \cdot \mathrm{s}^{-1}$ increases mechanical power by $1.37 \mathrm{~W} \cdot \mathrm{kg}^{-1}$, reducing to just 0.15

$476 \mathrm{~W} \cdot \mathrm{kg}^{-1}$ when running at $3 \mathrm{~m} \cdot \mathrm{s}^{-1}$. The practical significance of this assumption is therefore context 477 specific.

479 5) The mechanical work done to ventilate, circulate blood and other functions within the trunk and 480 limbs is not accounted for, which is often the case in biomechanical modelling.

482 Gray et al. (2018) recently proposed temporal classification of movement events e.g. walking 483 bouts, running bouts, contact events etc. and subsequent energy-based quantification of these 484 movement events in field-based games. The model presented and evaluated is proposed as a 485 method to quantify the mechanical demands of identified running events. The present analyses 486 have demonstrated how the model serves to account for the demands of constant low- and high487 speed running events, acceleration events and deceleration events, so that applied researchers and 488 practitioners understand how global load metrics such as mechanical work done $\left(\mathrm{J} \cdot \mathrm{kg}^{-1}\right)$ in a 489 running based session may be derived; in this case, from the well described relationships between 
490 running velocity and running kinematics (Gray et al., In Press; Pavei et al., 2019; Saibene \& 491 Minetti, 2003).

493 Users applying the model must remain cognisant of the assumptions outlined previously. The 494 authors readily acknowledge these limitations and consider the model to provide reasonable 495 estimates of mechanical demand and power outside a laboratory setting. Work estimates produced 496 by the model are also subject to the quality of velocity-time data from which it is based. As such 497 users, must also familiarise themselves with the validity and reliability of commercial GPS 498 receivers and data collection factors that impact data quality (Scott, Scott \& Kelly, 2016). 499 Furthermore, general application of the model to entire GPS field-sport match files is not 500 appropriate, as the model assumes forward running is the only gait adopted. Separate models 501 should be used to discretely evaluate other gaits and match events (Gray et al., 2018).

503 Given the proposed application of the model, and the low mechanical demand attributable to air 504 resistance during running (Pugh, 1971, 1976), the importance of including air resistance as a load 505 during team-sport training and competition, is questionable. Particularly, as players spend a 506 majority of time during team sport match play at low speeds (i.e. $<3 \mathrm{~m} \cdot \mathrm{s}^{-1}$ ) (Bangsbo et al., 2006;

507 Duthie et al., 2003; Gray \& Jenkins, 2010), where air resistance is negligible (Figure 2). As such 508 the authors note that whilst the inclusion of $W_{\text {air }}$ provides a more complete description, its inclusion 509 in applied practice may not be necessitated. Indeed, others readily omit this component (di 510 Prampero, Botter \& Osgnach, 2015) to simplify the analysis. 


\section{Conclusions}

513 This study presents a new approach to quantify the mechanical demands of intermittent running,

514 as measured using GPS technology. The running model presented and evaluated is proposed as

515 part of a broader energy-based solution to the quantification of field sport match demands via

516 micro-technology (Gray et al., 2018). The model uses established relationships between forward

517 running velocity and running kinematics to model the work done during a running bout. Whilst

518 this is based on several assumptions, the model provides reasonable approximations of mechanical

519 demand and power, that are responsive to varied running patterns, as evidenced in this analysis.

520 The present model may be considered an initial step toward achieving an optimal energy-based

521 method of quantifying load through micro-technology. Indeed, many attributes of this model could

522 be refined and improved upon through direct measurement rather than prediction e.g. stride

523 frequency, and/or experimental work to improve various components e.g. $W_{\text {limbs }}$. Modelled

524 mechanical power during extended overground running may also open new avenues for research

525 and possibly strengthen our understanding of running performance, just as power-based concepts

526 have done for cycling (Shearman, Dwyer, Skiba \& Townsend, 2016; Waldron, Gray, Furlan \&

527 Murphy, 2016).

528

529 Acknowledgments

530 The authors thank Lachlan Penfold and the Brisbane Lions AFC for supporting data collection

531 and P.E. di Prampero and his colleagues for discussion during the development of the presented

532 model.

533

534 Declaration of Interest Statement 
The authors report no conflict of interest

536

537

538

539

540

541

542

543

544

545

546

547

548

549

550

\section{References}

Arampatzis, A., Knicker, A., Metzler, V., \& Bruggemann, G. P. (2000). Mechanical power in running: a comparison of different approaches. Journal of Biomechanics, 33, 457-463.

Aughey, R. J. (2011). Applications of GPS technologies to field sports. International Journal of Sports Physiology and Performance, 6(3), 295-310.

Bangsbo, J., Mohr, M., \& Krustrup, P. (2006). Physical and metabolic demands of training and match-play in the elite football player. Journal of Sports Sciences, 24(7), 665- 674.

Blomqvist, C. G., \& Saltin, B. (1983). Cardiovascular adaptations to physical training. Annual Review of Physiology, 45(1), 169-189.

Bloomfield, J., Polman, R., \& O'Donoghue, P. (2007). Physical demands of different positions in FA Premier League soccer. Journal of sports science \& medicine, 6(1), 63.

Bourdon, P. C., Cardinale, M., Murray, A., Gastin, P., Kellmann, M., Varley, M. C., et al. (2017). Monitoring athlete training loads: consensus statement. International journal of sports physiology and performance, 12(s2), S2-161-S162-170.

Brooks, H. P., Andrews, M. H., Gray, A. J., \& Osborne, M. A. (2013). Comparison of models for the physiological estimation of internal mechanical power in Cycling. Journal of Science and Cycling, 2(1), 58.

Brueckner, J. C., Atchou, G., Capelli, C., Duvallet, A., Barrault, D., Jousselin, E., et al. (1991). The energy cost of running increases with distance covered. European Journal of Applied Physiology and Occupational Physiology, 62, 385-389.

Buttifant, D. (1999). Physiological and performance characteristics of Australian Football League players. Journal of Sports Sciences, 17, 808-809.

Cavagna, G. A. (2006). The landing-take-off asymmetry in human running. Journal of Experimental Biology, 209, 4051-4060.

Cavagna, G. A., \& Kaneko, M. (1977). Mechanical work and efficiency in level walking and running. Journal of Physiology, 268, 467-481.

Cavagna, G. A., Saibene, F., \& Margaria, R. (1964). Mechanical work in running. Journal of Applied Physiology, 19, 249-256. 
Chelly, S. M., \& Denis, C. (2001). Leg power and hopping stiffness: Relationship with sprint running performance. Medicine and Science in Sports and Exercise, 33(2), 326-333.

Cummins, C., Orr, R., O'Connor, H., \& West, C. (2013). Global positioning systems (GPS) and microtechnology sensors in team sports: a systematic review. Sports Medicine, 43(10), 1025-1042.

Davies, C. T. M. (1980). Effects of wind resistance on the forward motion of a runner. Journal of Applied Physiology: Respiratory, Environmental and Exercise Physiology, 48(4), 702-

di Prampero, P. E. (1986). The energy cost of human locomotion on land and in water. International Journal of Sports Medicine, 7(1), 55-72.

di Prampero, P. E., Botter, A., \& Osgnach, C. (2015). The energy cost of sprint running and the role of metabolic power in setting top performances. European Journal of Applied Physiology, 115(3), 451-469.

Doke, J., Donelan, J. M., \& Kuo, A. D. (2005). Mechanics and energetics of swinging the human leg. Journal of Experimental Biology, 208, 439-445.

DuBois, D., \& DuBois, E. F. (1916). A formula to estimate the approximate surface area if height and weight be known. Archives of Internal Medicine, 17, 863-871.

Duthie, G., Pyne, D. B., \& Hooper, S. (2003). Applied physiology and game analysis of rugby union. Sports Medicine, 33(13), 973-991.

Farley, C. T., \& Ferris, D. P. (1998). Biomechanics of walking and running: Center of mass movements to muscle action. Exercise and Sports Science Reviews, 26, 253- 285. of current methodology. Journal of the Australian Strength and Conditioning Association, 22(5), 95-98.

Gabbett, T. J., King, T., \& Jenkins, D. (2008). Applied physiology of rugby league. Sports Medicine, 38(2), 119-138. 
594 Gray, A., Price, M., \& Jenkins, D. (In Press). Predicting Temporal Gait Kinematics From

595

596

597

598

599

600

601

602

603

604

605

606

607

608

609

610

611

612

613

614

615

616

617

618

619

620

621

622

623

Running Velocity. The Journal of Strength \& Conditioning Research, Publish Ahead of Print. doi: 10.1519/jsc.0000000000003198

Gray, A. J., \& Jenkins, D. (2010). Match analysis and the physiological demands of Australian football. Sports Medicine, 40(4), 347-360.

Gray, A. J., Shorter, K., Cummins, C., Murphy, A., \& Waldron, M. (2018). Modelling Movement Energetics Using Global Positioning System Devices in Contact Team Sports: Limitations and Solutions. Sports Medicine, 1-12.

Halson, S. L. (2014). Monitoring training load to understand fatigue in athletes. Sports Medicine, 44(2), 139-147.

Holloszy, J. O., \& Coyle, E. F. (1984). Adaptations of skeletal muscle to endurance exercise and their metabolic consequences. Journal of Applied Physiology, 56(4), 831-838.

Impellizzeri, F. M., Rampinini, E., Coutts, A. J., Sassi, A., \& Marcora, S. M. (2004). Use of RPE-based training load in soccer. Medicine \& Science in Sports \& Exercise, 36(6), 1042-1047.

Ito, A., Komi, P. V., Sjodin, B., Bosco, C., \& Karlsson, J. (1983). Mechanical efficiency of positive work in running at different speeds. Medicine and Science in Sports and Exercise, 15(4), 299-308.

Jobson, S. A., Passfield, L., Atkinson, G., Barton, G., \& Scarf, P. (2009). The analysis and utilization of cycling training data. Sports Medicine, 39(10), 833-844.

Lambert, M. I., \& Borresen, J. (2010). Measuring training load in sports. International Journal of Sports Physiology and Performance, 5(3), 406-411.

Lathlean, T. J., Gastin, P. B., Newstead, S. V., \& Finch, C. F. (2019). A prospective cohort study of load and wellness (sleep, fatigue, soreness, stress, and mood) in elite junior Australian football players. International Journal of Sports Physiology and Performance, 14(6), 829-840.

Lee, C. R., \& Farley, C. T. (1998). Determinants of the center of mass trajectory in human walking and running. Journal of Experimental Biology, 201, 2935- 2944.

Lejune, T. M., Willems, P. A., \& Heglund, N. C. (1998). Mechanics and energetics of human locomotion on sand. Journal of Experimental Biology, 201, 2071- 2080. 
624 Malone, J. J., Lovell, R., Varley, M. C., \& Coutts, A. J. (2017). Unpacking the black box:

625

626

627

628

629

630

631

632

633

634

635

636

637

638

639

640

641

642

643

644

645

646

647

648

649

650

651

652 applications and considerations for using GPS devices in sport. International Journal of Sports Physiology and Performance, 12(s2), S2-18-S12-26.

Mann, R. A., \& Hagy, J. (1980). Biomechanics of walking, running and sprinting. American Journal of Sports Medicine, 8(5), 345- 350.

Minetti, A. E. (1998). A model equation for the prediction of mechanical internal work of terrestrial locomotion. Journal of Biomechanics, 31, 463- 468.

Nagahara, R., Matsubayashi, T., Matsuo, A., \& Zushi, K. (2014). Kinematics of transition during human accelerated sprinting. Biology Open, 3(8), 689-699.

Nardello, F., Ardigo, L. P., \& Minetti, A. E. (2011). Measured and predicted mechanical internal work in human locomotion. Human Movement Science, 30(1), 90-104. doi:

10.1016/j.humov.2010.05.012

Nilsson, J., Thorstensson, A., \& Halbertsma, J. (1985). Changes in leg movements and muscle activity with speed of locomotion and mode of progression. Acta Physiologica Scandinavica, 123, 457-475.

Osgnach, C., Poser, S., Bernardini, R., Rinaldo, R., \& di Prampero, P. E. (2010). Energy cost and metabolic power in elite soccer: A new match analysis approach. Medicine and Science in Sports and Exercise, 42(1), 170- 178.

Paradisis, G. P., Bissas, A., Pappas, P., Zacharogiannis, E., Theodorou, A., \& Girard, O. (2019). Sprint mechanical differences at maximal running speed: Effects of performance level. Journal of Sports Sciences, 37(17), 2026-2036.

Pavei, G., Zamparo, P., Fujii, N., Otsu, T., Numazu, N., Minetti, A. E., et al. (2019). Comprehensive mechanical power analysis in sprint running acceleration. Scandinavian Journal of Medicine \& Science in Sports.

Polglaze, T., \& Hoppe, M. W. (2019). Metabolic Power: A Step in the Right Direction for Team Sports. International Journal of Sports Physiology and Performance, 14(3), 407-411.

Pugh, I. G. C. E. (1971). The influence of wind resistance in running and walking and the mechanical efficiency of work against horizontal or vertical forces. Journal of Physiology, 213, 255-276. 
Pugh, I. G. C. E. (1976). Air resistance in sport. In E. Jokl, R. L. Anand \& H. Stoboy (Eds.), Medicine in Sport: Advances in Exercise Physiology (Vol. 9, pp. 149-164). Basel: Karger.

Saibene, F., \& Minetti, A. E. (2003). Biomechanical and physiological aspects of legged locomotion in humans. European Journal of Applied Physiology, 88, 297-316.

Saito, M., Kobayashi, K., Myashita, M., \& Hoshikawa, T. (1974). Temporal patterns in Running. In R. C. Nelson \& C. A. Morehouse (Eds.), Biomechanics IV (pp. 106- 111). Baltimore: University Park Press.

Schwellnus, M., Soligard, T., Alonso, J.-M., Bahr, R., Clarsen, B., Dijkstra, H. P., et al. (2016). How much is too much?(Part 2) International Olympic Committee consensus statement on load in sport and risk of illness. Br J Sports Med, 50(17), 1043-1052.

Scott, M. T., Scott, T. J., \& Kelly, V. G. (2016). The validity and reliability of global positioning systems in team sport: a brief review. The Journal of Strength \& Conditioning Research, 30(5), 1470-1490.

Shanebrook, J. R., \& Jaszczak, R. D. (1976). Aerodynamic drag analysis of runners. Medicine and Science in Sports, 8(1), 43-45.

Shearman, S., Dwyer, D., Skiba, P., \& Townsend, N. (2016). Modeling intermittent cycling performance in hypoxia using the critical power concept. Medicine and Science in Sports and Exercise, 48(3), 527-535.

Shuter, B., \& Aslani, A. (2000). Body surface area: DuBois and DuBois revisited. European Journal of Applied Physiology, 82, 250-254.

Soligard, T., Schwellnus, M., Alonso, J.-M., Bahr, R., Clarsen, B., Dijkstra, H. P., et al. (2016). How much is too much?(Part 1) International Olympic Committee consensus statement on load in sport and risk of injury. British Journal of Sports Medicine, 50(17), 10301041.

Taha, T., \& Thomas, S. G. (2003). Systems modelling of the relationship between training and performance. Sports Medicine, 33(14), 1061-1073.

Waldron, M., Gray, A., Furlan, N., \& Murphy, A. (2016). Predicting the sprint performance of adolescent track cyclists using the 3-minute all-out test. Journal of Strength and Conditioning Research, 30(8), 2299-2306. 
683 Walpert, R. A., \& Kyle, C. R. (1989). Aerodynamics of the human body in sport. Journal of $684 \quad$ Biomechanics, 22(10), 1096.

685 Ward Smith, A. J. (1984). Air resistance and its influence on the biomechanics and energetics of 686 sprinting at sea level and altitude. Journal of Biomechanics, 17(5), 339-347.

687 Wisbey, B., Montgomery, P. G., Pyne, D. B., \& Rattray, B. (2010). Quantifying movement demands of AFL football using GPS tracking. Journal of Science and Medicine in Sport, 13(5), 531-536. doi: 10.1016/j.jsams.2009.09.002

Young, W. B., Hepner, J., \& Robbins, D. W. (2012). Movement demands in Australian rules football as indicators of muscle damage. The Journal of Strength \& Conditioning Research, 26(2), 492-496.

Young, W. B., Newton, R. U., Doyle, T. L. A., Chapman, D., Cormack, S., Stewert, G., et al. (2005). Physiological and anthropometric characteristics of starters and non-starters and playing positions in elite Australian Rules Football: A case study. Journal of Science and Medicine in Sport, 8(3), 333-345.

Zamparo, P., Pavei, G., Monte, A., Nardello, F., Otsu, T., Numazu, N., et al. (2019). Mechanical work in shuttle running as a function of speed and distance: Implications for power and efficiency. Human Movement Science, 66, 487-496.

Zatsiorsky, V. M. (1997). The review is nice: I disagree with it. Journal of Applied Biomechanics, 13, 479- 483.

702 Zatsiorsky, V. M., Werner, S. L., \& Kaimin, M. A. (1994). Basic kinematics of walking: Step length and step frequency. A review. Journal of Sports Medicine and Physical Fitness, 34(2), 109-134.

705 
706 Tables

707

708 NONE.

709 
$710 \quad$ Figures

711

712 Figure 1.

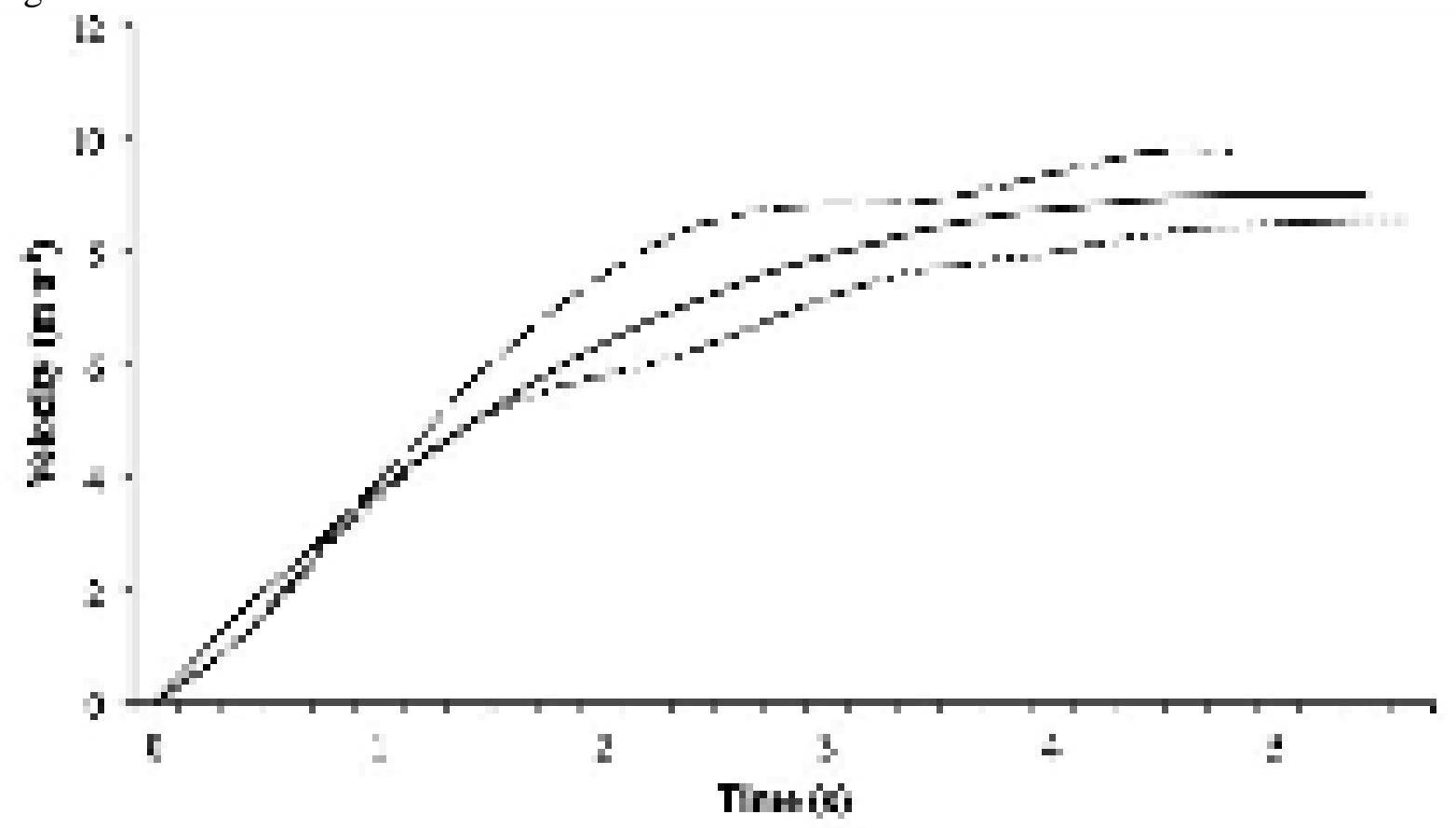

713

714

715 
716 Figure 2.
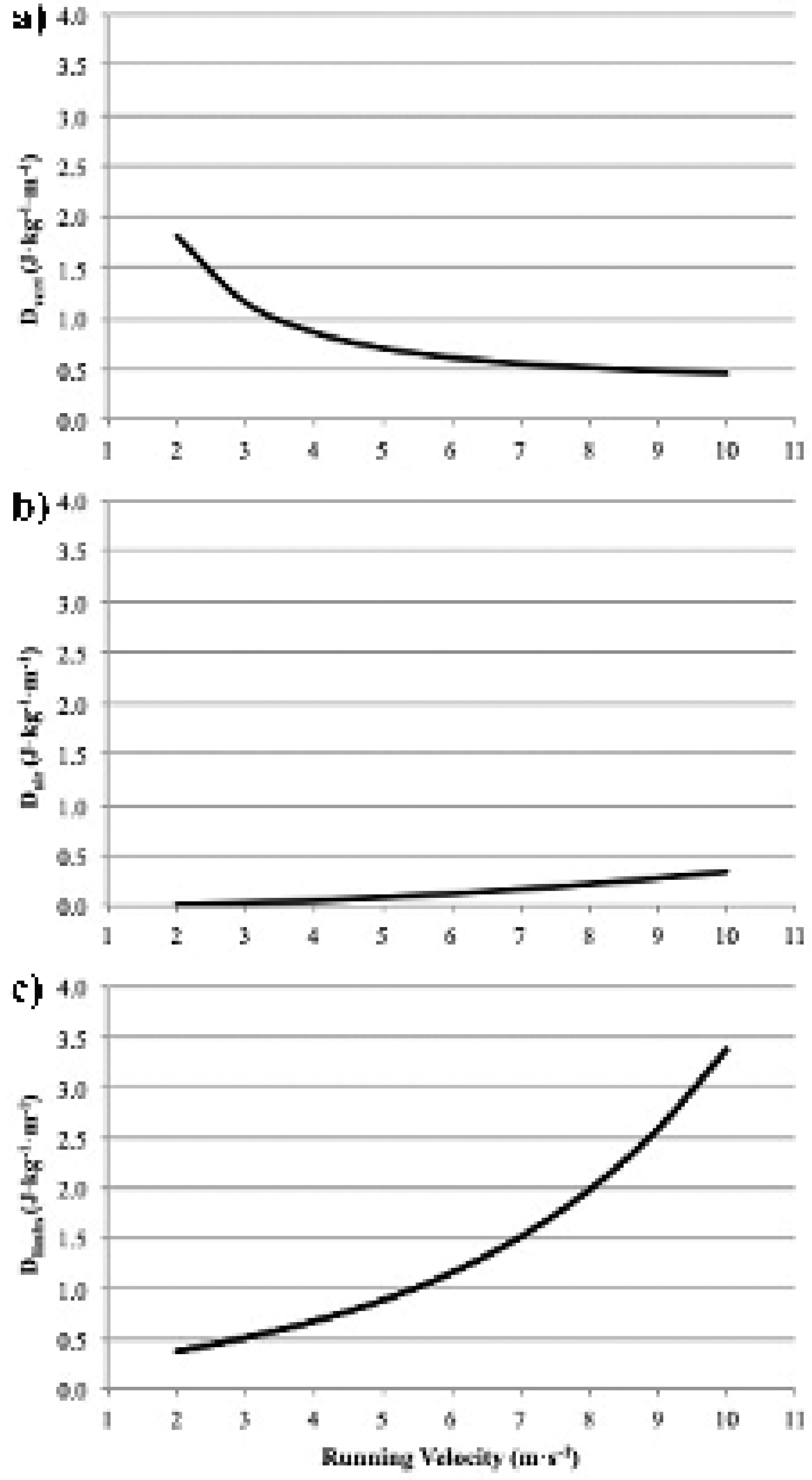
719 Figure 3.

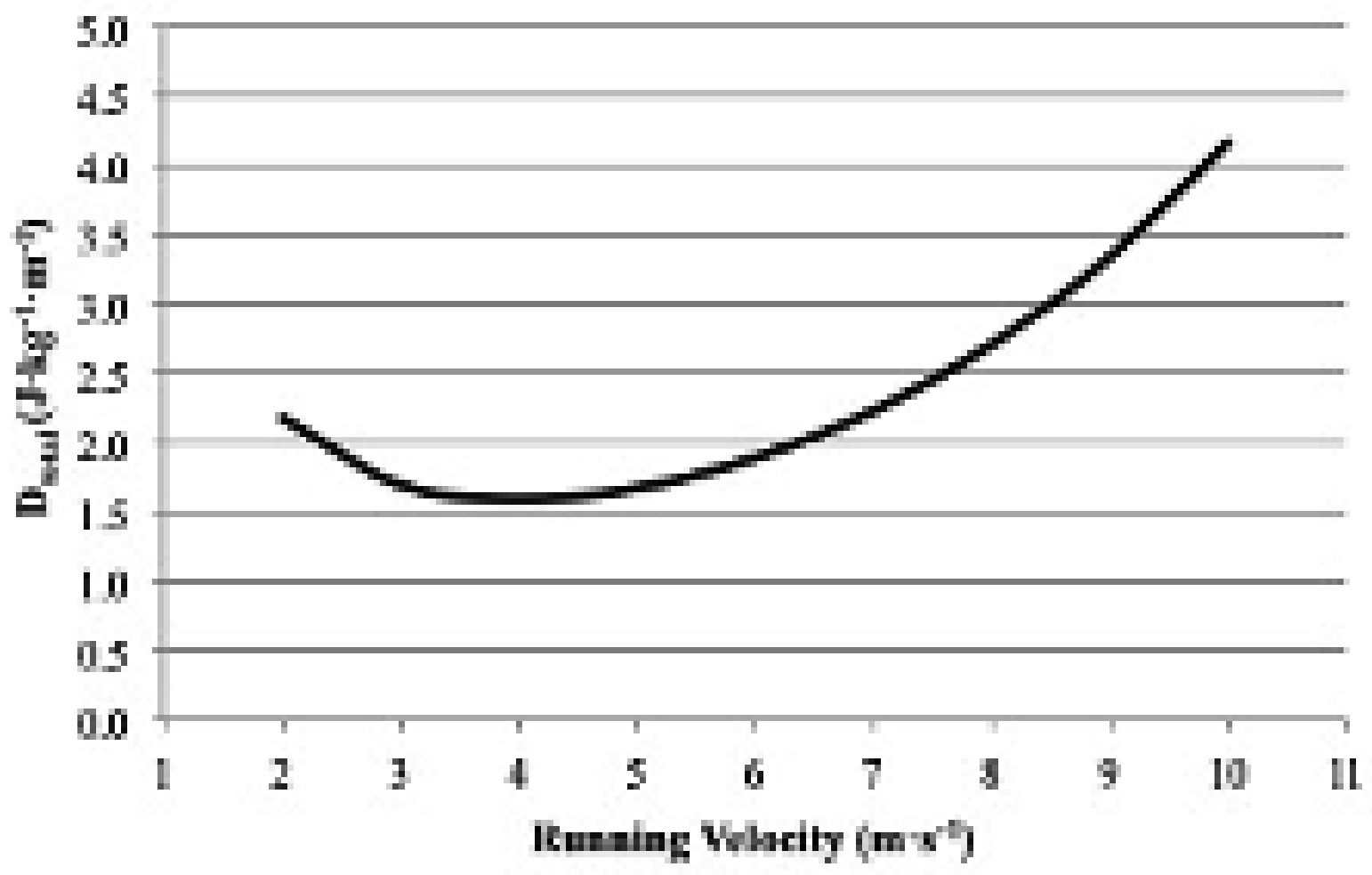

720

721

Figure 4.

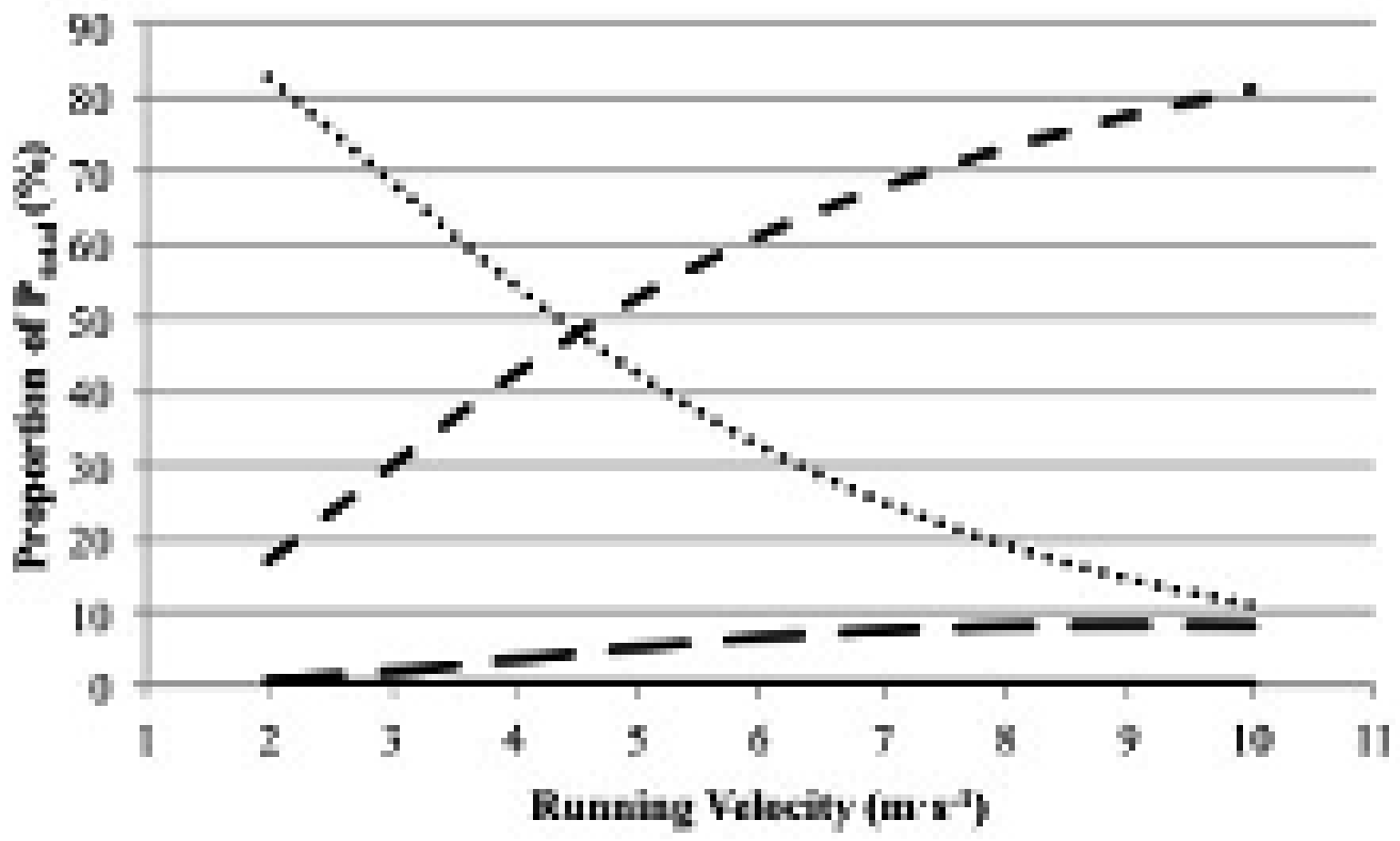


724 Figure 5.

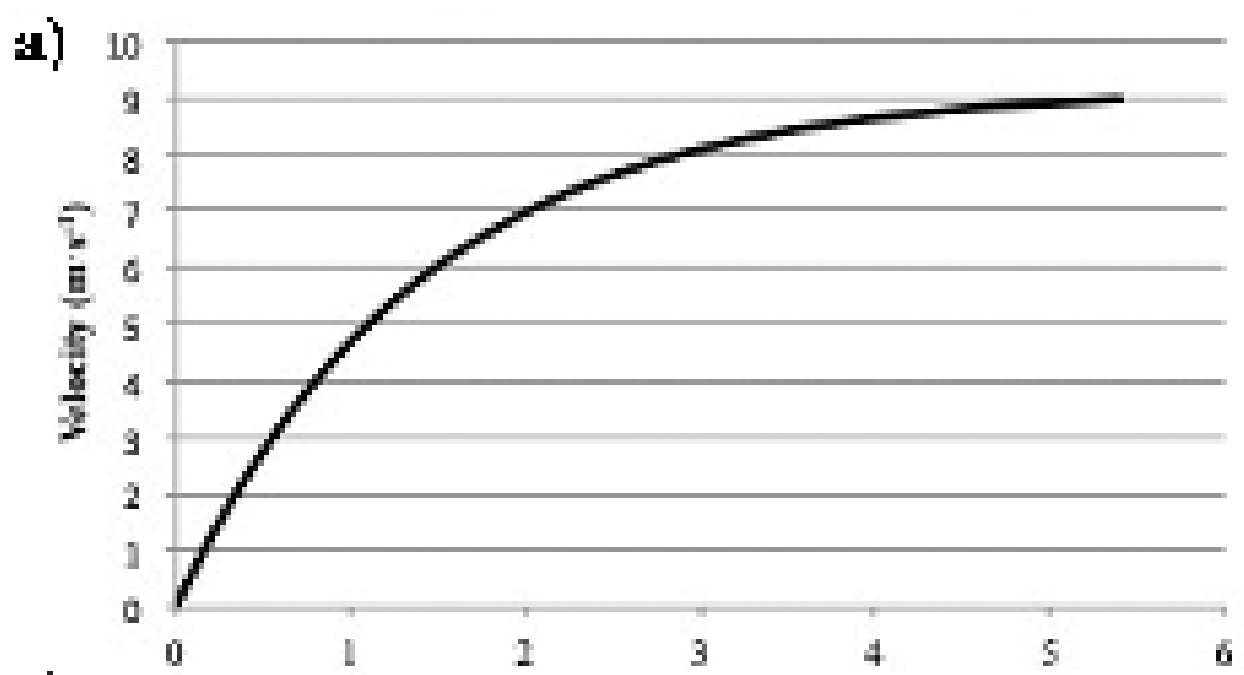

b)

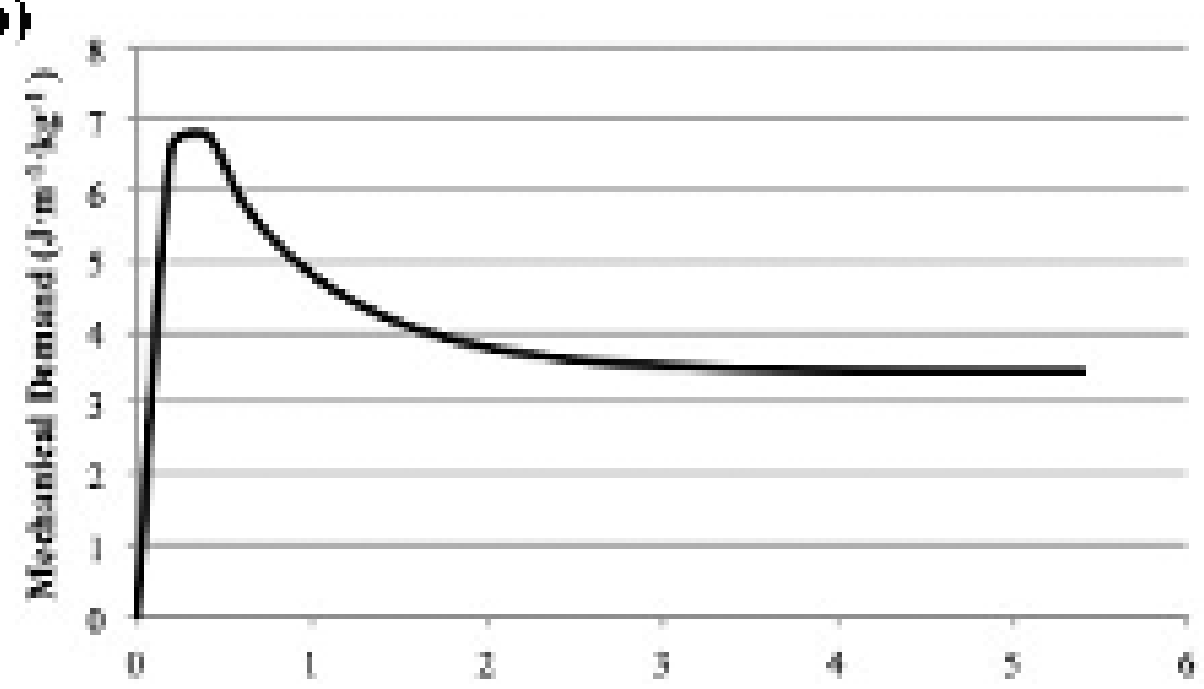

c)

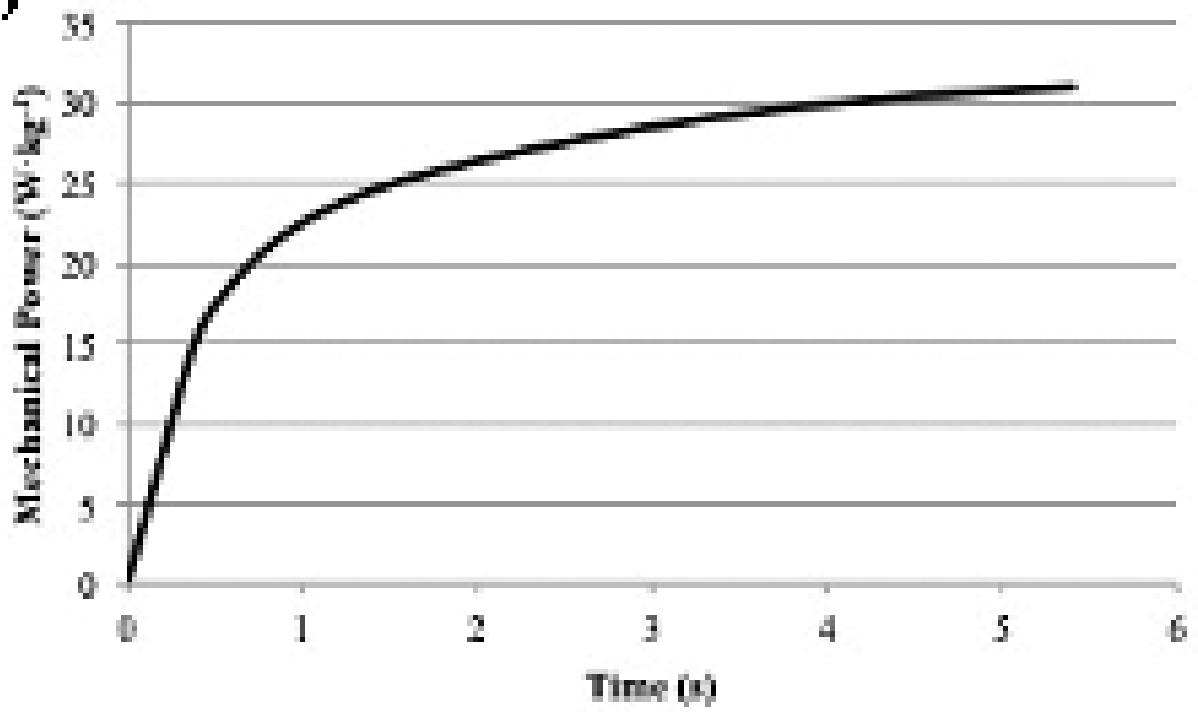


727 Figure 6.
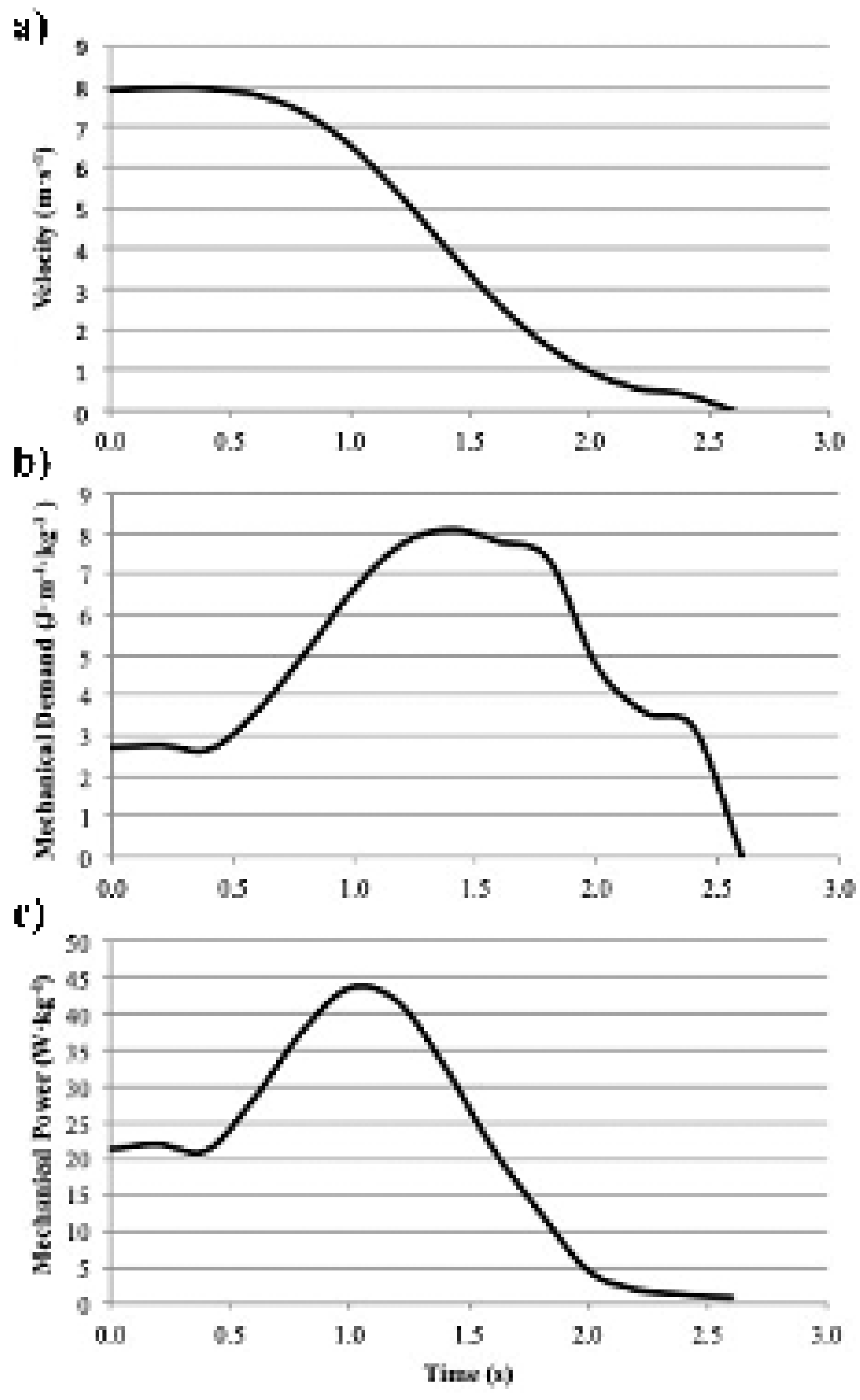

728 
$730 \quad$ Figure 7.

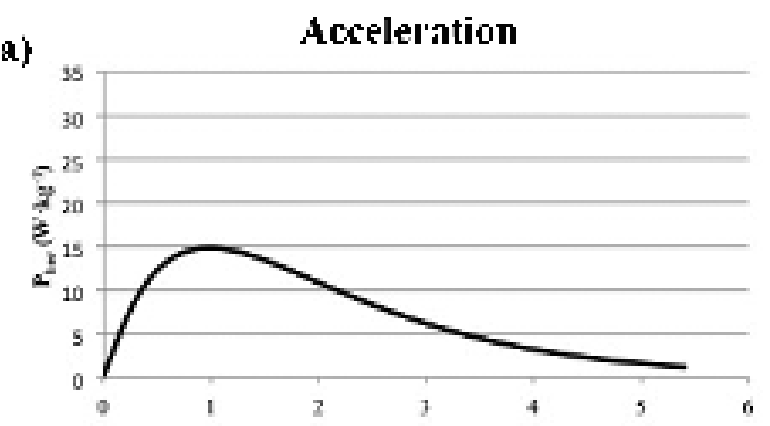

b)

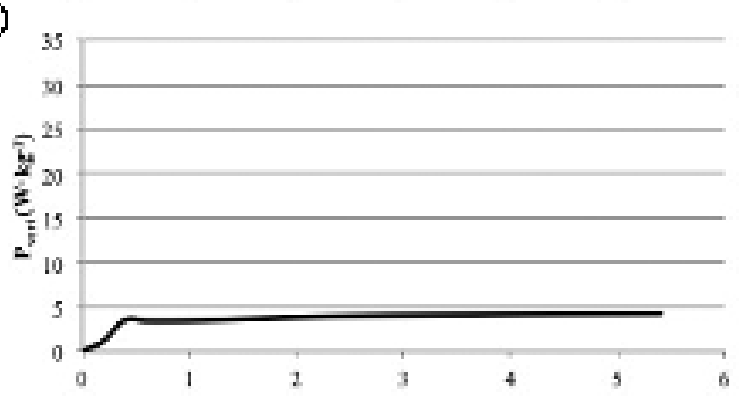

c)

d)
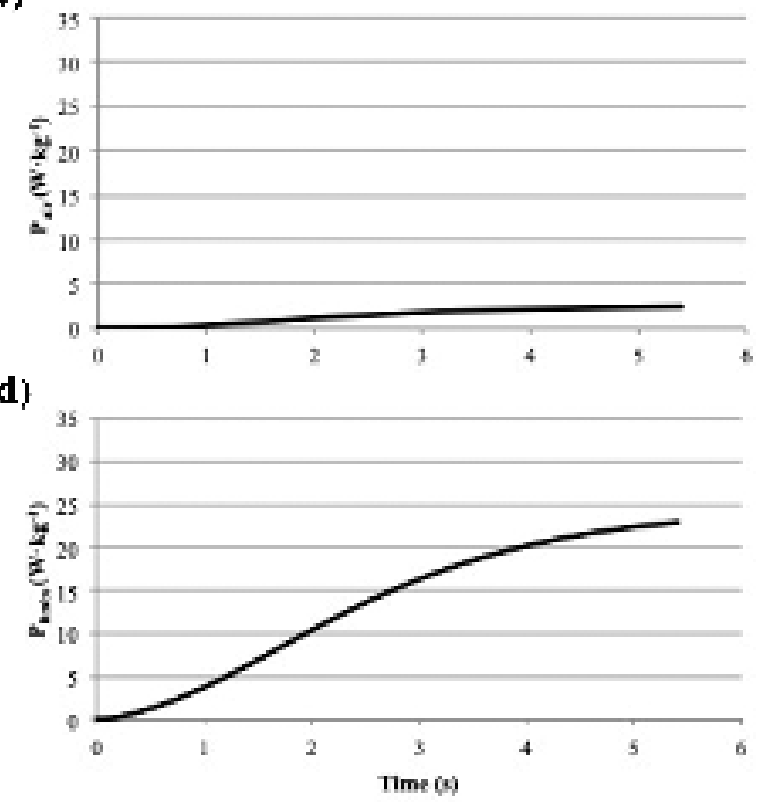

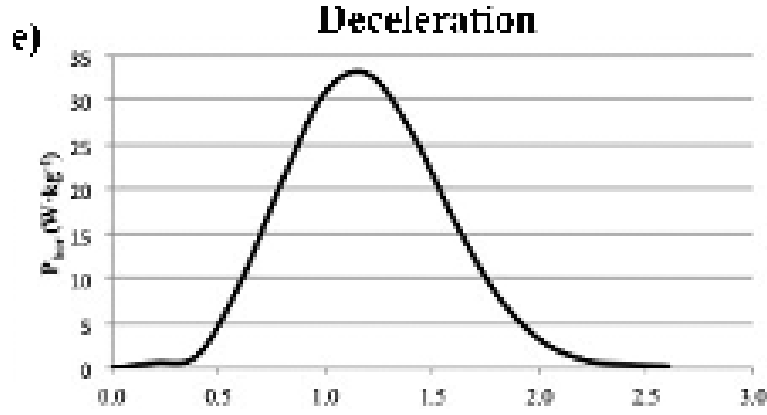

)

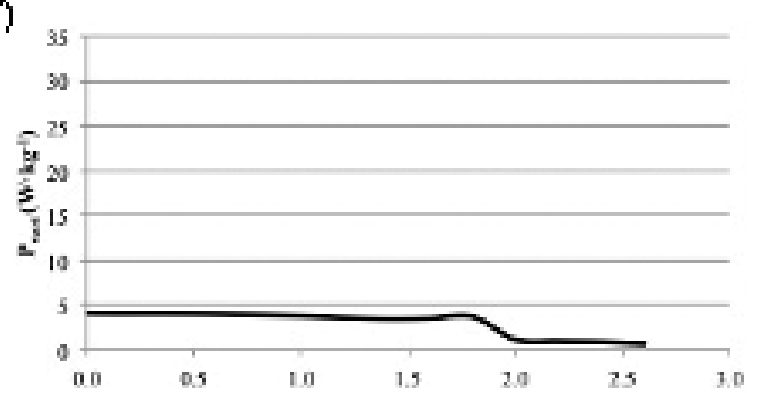

घ)

li)
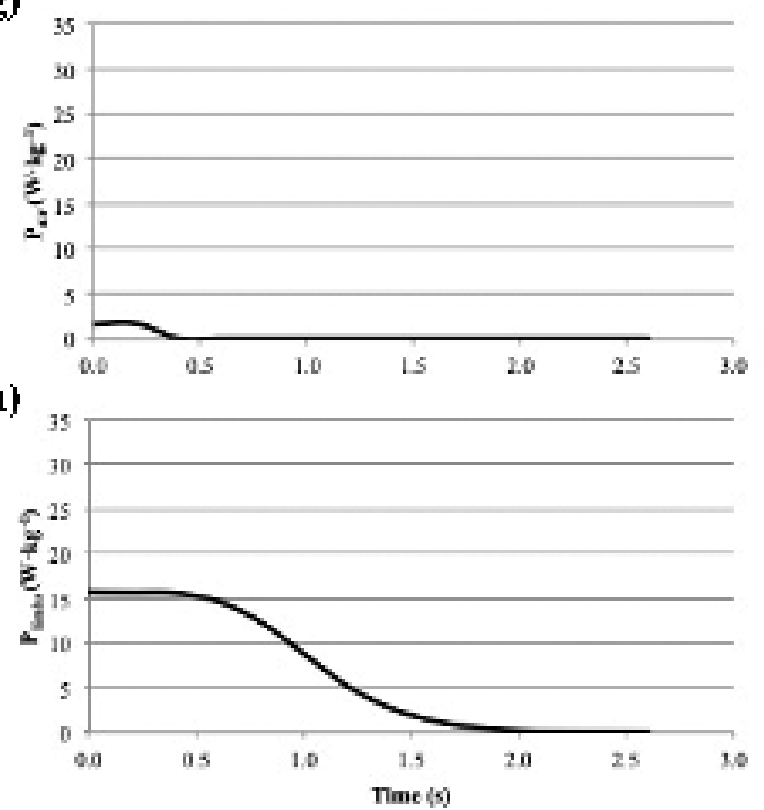
739

740 741

742

743

\section{Figure Captions}

Fig 1. Velocity curves from the fastest (long dashed line) and slowest (short dashed line) participants' $40 \mathrm{~m}$ sprints. The solid line is the exponential model $v_{t}=9.16 \times\left(1-e^{\frac{t}{1.4}}\right)$, which approximates the group's sprint performance, where $v$ is in $\mathrm{m} \cdot \mathrm{s}^{-1}$ and $t$ is in s.

Fig 2. The modelled mechanical demand $(D)$ i.e. work done per unit distance to a) raise and lower the COM $\left(D_{\text {vert }}{ }^{+}\right.$and $D_{\text {vert }}{ }^{-}$combined); b) overcome air resistance; and c) swing the limbs during constant velocity, overground running. Note: As horizontal acceleration and deceleration are zero, no horizontal work is done; therefore, $D_{\text {hor }}{ }^{+}$and $D_{\text {hor }}{ }^{-}$are not included.

Fig 3. The modelled total mechanical demand $\left(D_{\text {total }}\right)$ i.e. work done per unit distance during constant velocity, overground running. This relationship is well described by the $4^{\text {th }}$ order polynomial: $D_{\text {total }}=0.0015 v^{4}-0.0384 v^{3}+0.4282 v^{2}-1.975 v+4.7003$, where $D_{\text {total }}$ is in $\mathrm{J} \cdot \mathrm{kg}^{-1} \cdot \mathrm{m}^{-}$ ${ }^{1}$ and $v$ is in $\mathrm{m} \cdot \mathrm{s}^{-1}$.

Fig 4. The modelled relative contributions (\%) of $P_{\text {hor }}$ (solid line), $P_{\text {vert }}$ (dotted line), $P_{\text {air }}$ (long dashed line) and $P_{\text {limbs }}$ (short dashed line) to $P_{\text {total }}$ during constant velocity, overground running.

Fig 5. A kinematic and energetic description of a simulated $40 \mathrm{~m}$ sprint, including a) the velocitytime curve; b) the time-course of the modelled total mechanical demand $\left(D_{\text {total }}\right)$; and c) the timecourse of the modelled mechanical power $\left(P_{\text {total }}\right)$ of the running bout.

Fig 6. A kinematic and energetic description of a hard, voluntary deceleration performed by Participant 6, including a) the velocity-time curve; b) the time-course of the modelled total mechanical demand $\left(D_{\text {total }}\right)$; and c) the time-course of the modelled mechanical power $\left(P_{\text {total }}\right)$ of the running bout.

Fig 7. The time-course of the mechanical power curves for $P_{h o r}, P_{\text {vert }}, P_{\text {air }}$ and $P_{\text {limbs }}$ during the simulated 40 m sprint [panels a), b), c) and d), respectively]; and the hard, voluntary deceleration 
766 performed by Participant 6 [panels e), f), g) and h), respectively]. Note: the peak acceleration 767 during the $40 \mathrm{~m}$ sprint was $5.7 \mathrm{~m} \cdot \mathrm{s}^{-2}$, whilst the peak deceleration by Participant 6 was $-6.6 \mathrm{~m} \cdot \mathrm{s}^{-2}$. 768

769 